\title{
TEM and Optical Studies of Ni/NiO Nanoparticles in Ni-ion-implanted $\mathrm{Al}_{2} \mathrm{O}_{3}$
}

\author{
X.T. Zu, ${ }^{*}$ S. Zhu, ${ }^{* *}$ X. Xiang, ${ }^{*}$ L.M. Wang ${ }^{* *}$ \\ * Department of Applied Physics, University of Electronic Science and Technology of China, \\ Chengdu, 610054, P.R. China \\ ** Department of Nuclear Engineering and Radiological Sciences, University of Michigan, Ann \\ Arbor, MI 48109-2104, U.S.A.
}

Metallic nanoparticles embedded in insulators have been extensively studied because of pronounced optical effects, including surface plasmon resonance (SPR) absorption and strong third-order nonlinear optical (NLO) susceptibility [1]. These composites have drawn much attention due to applicability for all-optical-memory or switching devices and single electron transistors [2-4], etc. Therefore, thermal stability of the metallic nanoparticles is practically important, e.g., under laser irradiation in use for optical devices. In our study, the metallic Ni nanoparticles embedded in $\mathrm{Al}_{2} \mathrm{O}_{3}$ single crystals have been synthesized by ion implantation. The microstructure and optical properties of nanoparticles before and after annealing have been studied.

Metallic Ni nanoparticles in the near surface region of $\mathrm{Al}_{2} \mathrm{O}_{3}$ single crystals have been synthesized by ion implantation to a fluence of $1 \times 10^{17} / \mathrm{cm}^{2}$. NiO nanoparticles formed after annealing at $900^{\circ} \mathrm{C}$ for $1 \mathrm{~h}$ in air. Transmission electron microscopy (TEM), X-ray photoelectron spectroscopy (XPS) and optical absorption spectroscopy have been utilized to characterize the nanostructure and optical properties of nanoparticles in $\mathrm{Al}_{2} \mathrm{O}_{3}$. The TEM images showed that Ni nanopartilces with size ranging 1-5 nm in the near surface of $\mathrm{Al}_{2} \mathrm{O}_{3}$ grew to $\mathrm{NiO}$ nanoparticles with size ranging 6-25 $\mathrm{nm}$ after annealing. XPS results proved the charge states of these nanoparticles. A SAD pattern showing Ni nanoparticles with lattice parameter $a=0.352 \mathrm{~nm}$. A high-resolution electron microscopy (HREM) image indicated the Ni-implanted area had been entirely amorphized. The amorphous area of $\mathrm{Al}_{2} \mathrm{O}_{3}$ matrix was partially recrystallized after annealing. A broad absorption band peaked at 400 $\mathrm{nm}$ was observed, which was ascribed to the surface plasmon resonance absorption of $\mathrm{Ni}$ nanoparticles. After annealing at $900^{\circ} \mathrm{C}$, the SPR absorption band disappeared and a UV absorption band peaked at $306 \mathrm{~nm}$ due to $\mathrm{NiO}$ can be observed.

\section{Reference}

[1] A. Meldrum et al., Advanced Materials 13 (2001) 1431.

[2] L. Yang et al., Applied Physics A 62 (1996) 403.

[3] P. Chakraborty, Journal of Material Science 33 (1998) 2235.

[4] A. Nakajima et al., Applied Physics Letter 73 (1998) 1071.

[5] This work was supported financially by the NSAF Joint Foundation of China （10376006） and by Program for New Century Excellent Talents in University. 


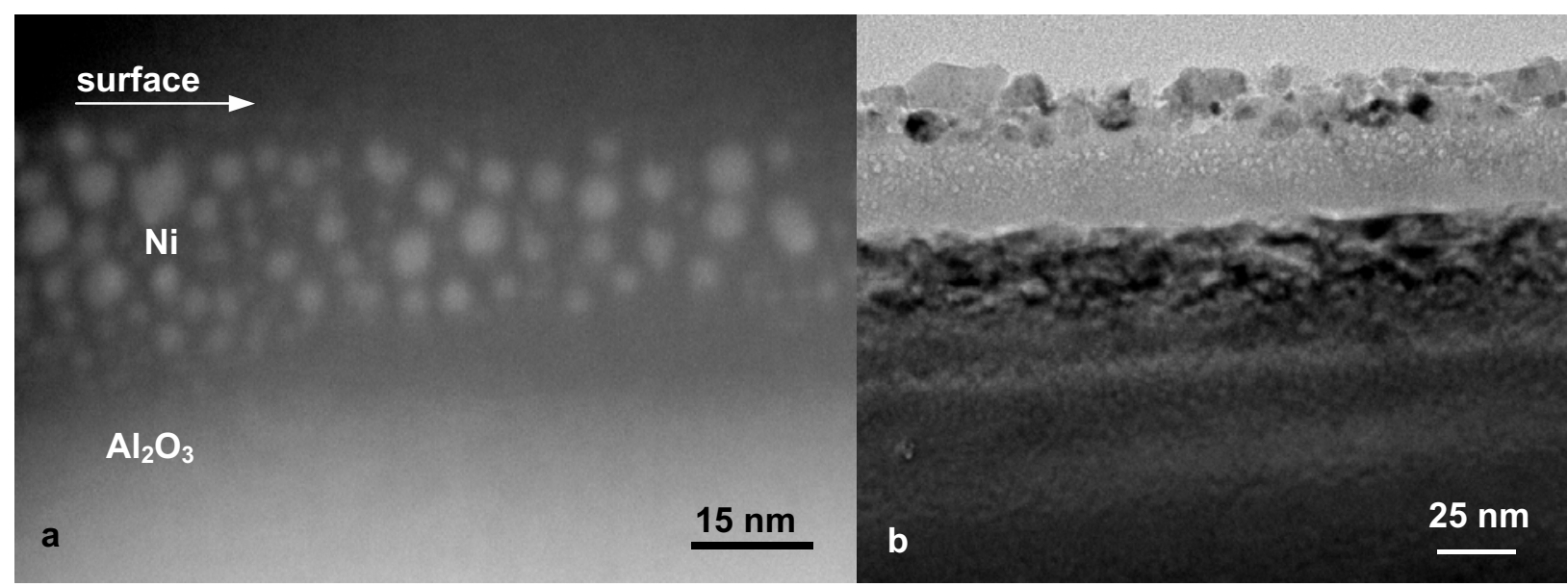

Fig. 1. A HAADF STEM cross-sectional image (a) showing nearly spherical Ni nanoparticles with size of $1-5 \mathrm{~nm}$ in diameter in the near surface region of $\mathrm{Al}_{2} \mathrm{O}_{3}$; A bright-field cross-sectional image (b) showing $\mathrm{NiO}$ nanoparticles with size of $6-25 \mathrm{~nm}$ formation after annealing at $900^{\circ} \mathrm{C}$ for $1 \mathrm{~h}$ in air.

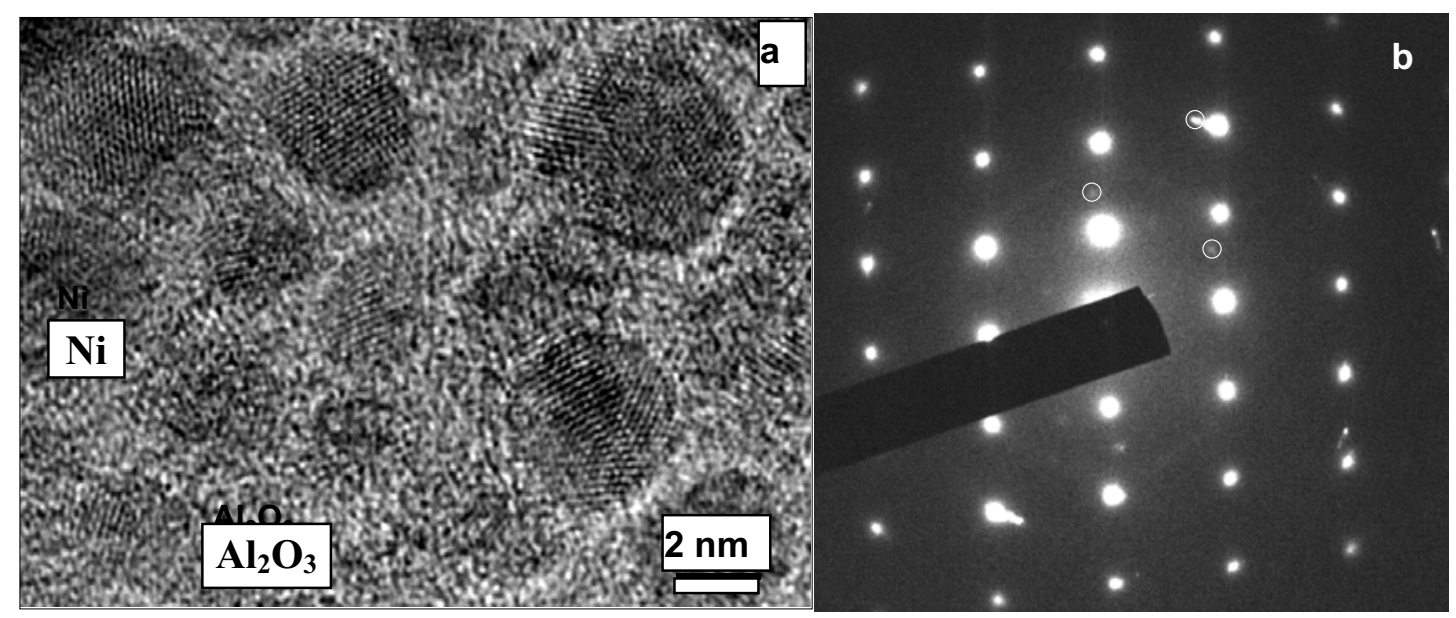

Fig. 2. A HREM image (a) indicating the Ni-implanted area entirely amorphized; A SAD pattern (b) indicating Ni nanoparticles with lattice parameter $a=0.352 \mathrm{~nm}$.
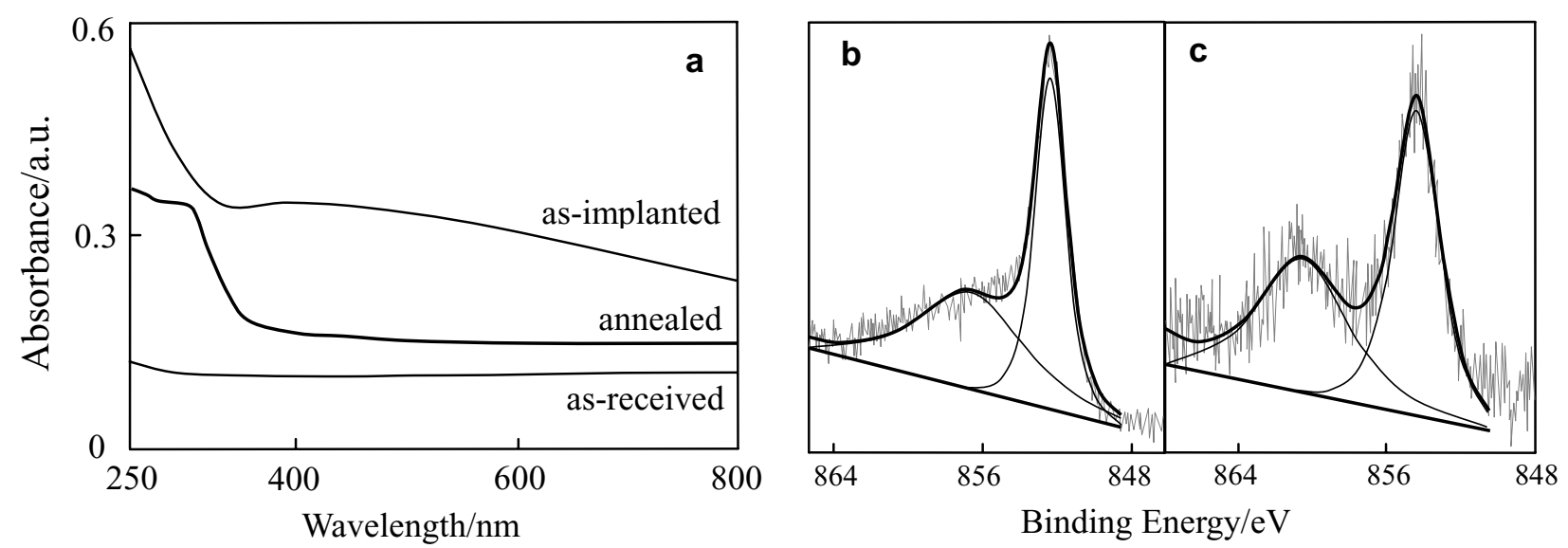

Fig. 3. Absorption spectra (a) showing the SPR band of Ni nanopraticles peaked at $400 \mathrm{~nm}$ and the band of $\mathrm{NiO}$ nanoparticles peaked at $306 \mathrm{~nm}$; XPS spectra of $\mathrm{Ni}_{2 \mathrm{p} 3 / 2}$ core level showing the charge states of $\mathrm{Ni}^{0}$ and $\mathrm{Ni}^{2+}(\mathrm{NiO})$ before (b) and after (c) annealing, respectively. 